\title{
Model HULIS compounds in nanoaerosol clusters - investigations of surface tension and aggregate formation using molecular dynamics simulations
}

\author{
T. Hede' ${ }^{1}$ X. Li ${ }^{2,3}$, C. Leck ${ }^{1}$, Y. Tu ${ }^{2}$, and H. Ågren ${ }^{2}$ \\ ${ }^{1}$ Department of Meteorology, Stockholm University, 10691 Stockholm, Sweden \\ ${ }^{2}$ Department of Theoretical Chemistry, School of Biotechnology, Royal Institute of Technology, 10691 Stockholm, Sweden \\ ${ }^{3}$ Laboratory for Advanced Materials and Institute of Fine Chemicals, East China University of Science and Technology, \\ Shanghai 200237, China
}

Received: 17 January 2011 - Published in Atmos. Chem. Phys. Discuss.: 1 March 2011

Revised: 29 June 2011 - Accepted: 30 June 2011 - Published: 8 July 2011

\begin{abstract}
Cloud condensation nuclei act as cores for water vapour condensation, and their composition and chemical properties may enhance or depress the ability for droplet growth. In this study we use molecular dynamics simulations to show that model humic-like substances (HULIS) in systems containing 10000 water molecules mimic experimental data well referring to reduction of surface tension. The model HULIS compounds investigated in this study are cis-pinonic acid (CPA), pinic acid (PAD) and pinonaldehyde (PAL). The structural properties examined show the ability for the model HULIS compounds to aggregate inside the nanoaerosol clusters.
\end{abstract}

\section{Introduction}

Understanding climate change is of utmost importance to mankind, since the effects of changes in the climate, both on regional and global scale, severely alter the conditions for life for a vast majority of the species on Earth. The Intergovernmental Panel on Climate Change (IPCC) states in the Forth Assessment Report (AR4) that a major uncertainty in the radiative forcing components of the atmosphere is due to clouds (Forster et al., 2007). Therefore it is of interest to refine the representation of clouds in the climate models.

Clouds cannot form unless there is a high relative humidity and presence of Cloud Condensation Nuclei $(\mathrm{CCN})$, that

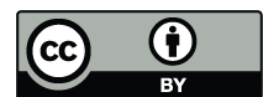

Correspondence to: C. Leck

(lina@misu.su.se) is, the number of aerosol particles available for uptake or condensation of water vapour. The most widely used theory that describes a process in which water vapour condenses and forms liquid cloud drops was developed by the Swedish meteorologist Hilding Köhler in the beginning of the $20^{\text {th }}$ century (Köhler, 1936) and is based on equilibrium thermodynamics. It combines the change in saturation vapour pressure due to a curved surface (the Kelvin effect), and to the solute (the Raoult's Law). At that time only soluble inorganic particles such as sea salt were thought to act as CCN. However, present knowledge concerning the aerosol multiphase system has identified that its organic components contribute and play a crucial role in the formation of cloud droplets in their ability to lower the surface tension for the water uptake (Novakov and Penner, 1993; Shulman et al., 1996; Facchini et al., 1999b; Rodhe, 1999).

Observations of airborne aerosol organic mass in urban areas have identified several surface active compounds, where humic-like substances (HULIS) are found abundant (Cini et al., 1996; Decesari et al., 2001; Facchini et al., 1999a, 2000; O'Dowd et al., 2002; Samburova et al., 2005). Cispinonic acid (CPA), which is an oxidation product from terpene evaporating from trees, is an organic acid belonging to a model group resembling HULIS. Surprisingly CPA has also been detected in polar regions, where there is little vegetation (Fu et al., 2009). This is either suggested to depend on long range transport or local/regional marine sources of terpenes. Closely related to CPA are two potentially surface active compounds, pinic acid (PAD) and pinonaldehyde (PAL). Humic acid differ somewhat from HULIS found in aerosol samples, and model compounds, like CPA, PAD and PAL are

Published by Copernicus Publications on behalf of the European Geosciences Union. 

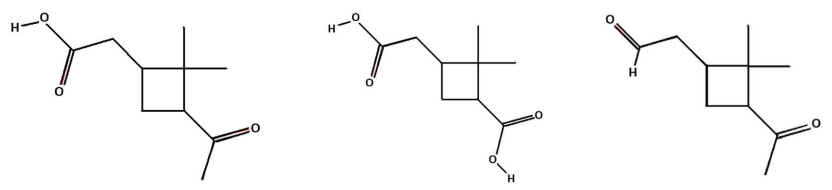

Cis-Pinonic acid (CPA)

Pinic Acid (PAD)

Pinonaldehyde (PAL)

$\mathrm{C}_{10} \mathrm{H}_{16} \mathrm{O}_{3}$

$\mathrm{C}_{9} \mathrm{H}_{14} \mathrm{O}_{4}$

$\mathrm{C}_{10} \mathrm{H}_{16} \mathrm{O}_{2}$

Fig. 1. Molecular structures of the three model HULIS compounds simulated in this study.

often used to describe the properties of HULIS (Kiss, 2005). The surface tension reduction has however been determined experimentally only for one of the above identified model HULIS acids, that is, CPA (Shulman et al., 1996; Varga et al., 2007; Kiss et al., 2005). The chemical structures of CPA, PAD, and PAL are shown in Fig. 1:

The underlying objective in this novel study is to use molecular dynamics (MD) simulations to investigate surface tension for clusters of water and surfactants (CPA, PAD and PAL) of atmospheric relevance; to our knowledge the latter two compounds have not been experimentally determined previously. In the case of CPA a direct comparison is made with the experimental data by Shulman et al. (1996). Previous work by Nijmeijer et al. (1992), Zakharov et al. (1998), and Chakraborty and Zachariah (2008), have used MD to determine surface tension for water clusters. However, these studies are limited to water and fatty acids. We believe that the compounds studied will be good representatives for other surfactants in the atmosphere.

\section{Theoretical background}

\subsection{MD simulations}

MD simulations describe the motion of atoms using Newtonian classical mechanics equations of motion (van der Spoel et al., 2005; Leach, 2001). In MD simulations, the Newton's equations of motion are solved numerically to evolve the atoms. The advantage of the MD simulation approach is that one can follow the motion of any atom based on the trajectory generated from the simulations, which is very hard for an experimental study to achieve. Therefore, MD simulations can provide us with detailed information about a system, such as the structure and dynamic properties. Furthermore, the effects of experimental conditions, such as pressure, temperature, on a system can also be studied through MD simulations.

The quality of an MD simulation is determined by the inter-atomic interactions, which can be modelled by incorporating a quantum chemistry calculation code into an MD simulation program, or simply by a predetermined molecular mechanical force field. With the currently available su-

per computers, the quantum chemistry calculation may cover around a hundred atoms and the corresponding MD simulation may be carried out at a time scale of a few hundred picoseconds. However, an MD simulation can be used to simulate a system involving as large as $\sim 10^{5}$ atoms and at a time scale as long as $\sim 10^{2}$ nanoseconds when a force field is used to describe the interaction between the atoms.

In order to reach lower concentrations of the model HULIS compounds representative for atmospheric conditions, it is necessary that the inter-atomic interactions be described by a force field and the corresponding MD simulations be run on super computers. Since the development of computer science is very fast, the opportunity to go from nuclei mode $(0.005$ to $0.025 \mu \mathrm{m}$ diameter) to accumulation mode ( 0.1 to $2.5 \mu \mathrm{m}$ diameter) is within reach.

\subsection{Köhler theory}

Köhler theory (1936) is as mentioned in the introduction used to predict the water vapour supersaturation of the air needed to condensate water vapour on existing $\mathrm{CCN}$ of various diameters according to Eqs. (1)-(4).

$$
S=\frac{A}{d}-\frac{B}{d^{3}}
$$

where $A / d$ is the Kelvin effect that depends on the curvature of the droplet and $B / d^{3}$ is the Raoult effect which is dependent on the solution of compounds in the droplet.

$A=\frac{4 \sigma M_{\mathrm{W}}}{\rho_{\mathrm{W}} R T}$

where $\sigma$ is the surface tension. For pure water the experimental value is $72.8 \mathrm{mN} \mathrm{m}^{-1}$ at $20^{\circ} \mathrm{C}$. $M_{\mathrm{W}}$ is the molar weight of water. $\rho_{\mathrm{W}}$ is the density of water. $R$ is the universal gas constant $\left(8.314 \mathrm{~J} \mathrm{~K}^{-1} \mathrm{~mol}^{-1}\right)$ and $T$ is the temperature.

$B=\frac{6 m_{\mathrm{S}} M_{\mathrm{W}}}{\pi \rho_{\mathrm{W}} M_{\mathrm{S}}}$

In Eq. (3), which is referred to as the Raoults law, $m_{\mathrm{S}}$ is the mass of the solute, and $M_{\mathrm{S}}$ is the molar weight of the solute. Sometimes the van't Hoff factor $i$ is multiplied with $B$

$B^{\prime}=B i$

Then $i \sim v \omega$, where $v$ is the number of ions produced from one solute molecule and $\omega$ is the molar osmotic coefficient of the solute in solution. However, the van't Hoff factor is often set to unity (Sorjamaa et al., 2004).

\subsection{Szyszkowski equation}

The Köhler Eq. (2) uses a constant value of surface tension independent of droplet diameter. This means that the effect of dissolution during droplet growth is not considered. To make the Köhler theory as relevant as possible for atmospheric conditions, the effect of the concentration 
Table 1. Aggregation formation in the simulations of nanoaerosol systems.

\begin{tabular}{ll}
\hline System simulated & Aggregate formation \\
\hline $13 \mathrm{CPA}+10000$ water & No \\
$27 \mathrm{CPA}+10000$ water & No \\
$54 \mathrm{CPA}+10000$ water & Yes \\
$81 \mathrm{CPA}+10000$ water & Yes \\
$162 \mathrm{CPA}+10000$ water & Yes \\
$13 \mathrm{PAD}+10000$ water & No \\
27 PAD + 10000 water & Yes, not so pronounced* \\
54 PAD + 10000 water & Yes \\
81 PAD + 10000 water & Yes \\
162 PAD + 10000 water & Yes, near surface \\
13 PAL + 10000 water & No \\
27 PAL + 10000 water & No \\
54 PAL + 10000 water & No \\
81 PAL + 10000 water & Yes, not so pronounced* \\
162 PAL + 10000 water & Yes, near surface \\
\hline
\end{tabular}

* Less than 10 molecules in the aggregate.

of the dissolved organic surfactant on cloud drop activation and growth has to be taken into account. An attempt to account for this is to introduce the empirical relationship developed by Szyszkowski (1908) which has later been improved (Meissner and Michaels, 1949; Facchini, 1999)

$$
\frac{\Delta \sigma}{\sigma}=-D \ln (1+C \cdot E)
$$

Here, $C$ is the concentration of the dissolved surfactant, and $D$ and $E$ are constants specific for each compound. The notations $D$ and $E$ have been chosen to distinguish from the constants $A$ and $B$ in the Köhler equation.

\section{Calculation details}

Water clusters containing different organic molecules (Table 1) were considered. The SPC/E water model (Berendsen, 1987) and the OPLS force field (Jorgensen, 1996) were used to describe the water molecules and the organic molecules, respectively. As we use a force field to describe the interactions between the atoms, it is assumed that the non-ideal interactions of organic molecules with water consist only of electrostatic and van der Waals interactions. The SPC/E water model consists of three sites representing one oxygen and two hydrogen atoms, respectively, with the inter-molecular interactions optimized according to experimentally measured properties of liquid water. Similarly, in the OPLS force field, the inter-atomic interactions have been parameterized to fit experimental properties of liquids such as density and heat of vaporization, and a recent study has shown that the solvation free energy is nicely reproduced by the OPLS force field (Shivakumar et al., 2010). Although this force field is not specially tailored for the organic acids in this study, the parameterization protocol ensures the transferability of the parameters. Our previous paper (Li et al., 2010) also supported the use of the OPLS force field.

For each cluster, the initial structure was generated using the GROMACS (Hess et al. 2005; Spoel et al., 2008) utility "genbox". First, organic molecules were randomly inserted into a simulation box of $6.8 \times 6.8 \times 6.8 \mathrm{~nm}^{3}$ and then 10000 water molecules were added into the box. Thereafter, the box size was increased by $6.0 \mathrm{~nm}$ along each axis to minimize the interaction between the cluster and its periodic images so that the artifact caused by the use of the periodic boundary condition was minimized. The initial structure thus obtained was further optimized using the steepest descent and conjugate gradient methods.

MD simulations were conducted using the GROMACS simulation package. For further reading concerning details in this section, we refer to GROMACS user manual version 4.0 (Spoel et al., 2005). In MD simulations, we employed the canonical (NVT) ensemble, with temperature maintained at $286 \mathrm{~K}$ by the Nosé-Hoover method. This method is developed as an extended-ensemble approach, in other words, the Hamiltonian of the system is extended by introducing a thermal reservoir and a friction term in the equations of motion. This approach has been shown to produce a correct canonical ensemble (Hoover, 1985). For the organic molecules, the bonds containing hydrogen atoms were constrained by the LINCS algorithm (Hess, 1997; Hess, 2007); and for water molecules, they were kept rigid by the SETTLE algorithm (Miyamoto, 1992). The time step used was 2 fs. A cutoff distance of $10 \AA$ was used to truncate the inter-atomic interactions and the Coulomb interaction beyond the cutoff distance was recovered by the particle mesh Ewald method (Darden, 1993; Essmann, 1995).

For each cluster, the equilibration was done during an MD simulation of $8 \mathrm{~ns}$. Thereafter, a $1 \mathrm{~ns}$ production simulation was carried out. During the simulations, the trajectories were recorded at every $1 \mathrm{ps}$ (500 steps). The trajectories were later used to study the structures of the clusters and to evaluate the surface tension of the clusters. The trajectories and their graphical representation could be followed using the VMD package (Humphrey et al., 1996). For details on the method to calculate the surface tension, we refer to Li et al. (2010).

In this study, we aimed to simulate the structures of the organic acid-water clusters, for instance the formation of the aggregate driven by entropy effects. We also paid attention to the surface tension of the clusters, which provides insight into the indirect effect of the organic acids on climate. The algorithms and parameters mentioned above ensure reasonable description of these properties, such as the structures and the surface tension, of the systems, which have been proved through comparison with experimental data.

Figures $2 \mathrm{a}-\mathrm{c}$ show how a cluster $(162 \mathrm{CPA}+10000$ water molecules) is formed. At first, CPA 162 molecules were inserted into the simulation box in which the molecules are 
randomly distributed (Fig. 2a). Then 10000 water molecules were inserted into the box as well. As can be seen, the cluster thus generated is of the cubic form (Fig. 2b). However, during the simulation, the molecules inside the box gradually form a nano-sized droplet - a spherical cluster. Figure 2c illustrates the structure of the cluster after $8 \mathrm{~ns}$ of simulation.

The typical simulation time required for $1 \mathrm{~ns}$ trajectory is $50 \pm 10 \mathrm{~h}$ with two AMD quad-core CPUs, run on the Ekman supercomputer at the center for high performance computing (PDC), Royal Institute of Technology (KTH) in Sweden.

\section{Results and discussion}

\subsection{Aggregate formation}

As reported in our previous work (Li et al., 2010), CPA could easily move from the interior of a droplet to reside on the surface, since CPA is a surface-active molecule. This behavior was expected in this study. However, during the equilibration of the systems described in Table 1, we found that not all the CPA molecules moved to the surface. In fact, there was an accumulation of molecules in the inside of the cluster so that a formation of an aggregate appeared. Table 1 shows when aggregation appeared in the simulations that we refer to as systems of various contents of model HULIS compounds.

However, none of the systems containing 13 or 27 molecules of surfactant showed a real tendency for aggregation formation. This indicates a micelle type of dynamics (Tanford, 1973) with critical micelle concentration (CMC) as a threshold for formation of such aggregates.

The behavior of aggregate formation is different from what was reported in a previous study by Li et al. (2010) where all CPA molecules moved to the surface in clusters consisting of 1000, 2000 and 5000 water molecules. The low solubility of CPA, $3.7 \mathrm{~g} \mathrm{~L}^{-1}$ (Tuckermann, 2007) indicates that CPA molecules may not dissolve in water, but rather aggregate when there are a large number of CPA molecules in a cluster. The model HULIS compounds molecules aggregate as a result of the so called hydrophobic effect (Tanford, 1973), where the "shell" of water molecules around the model HULIS compounds molecules is reduced when hydrophobic parts of the molecule are "hidden" and packed together, as well as hydrophilic parts are creating hydrogen bonds on the surface of the aggregate. The hydrophobic effect is mainly driven by an increase of entropy in the system. In a larger water cluster there is enough space (volume) to form such a solvation shell. The impact of limited solubility is indirectly accounted for, since the values for surface tension are computed with aggregation of a large part of surfactants. The surfactants in the aggregate do not contribute to the lowering of the surface tension, and the reason for aggregation is partly due to the low solubility.

Figure 3a shows the radial number density of the system with $162 \mathrm{PAL}$ and 10000 water molecules. Figure $3 \mathrm{~b}$ is a

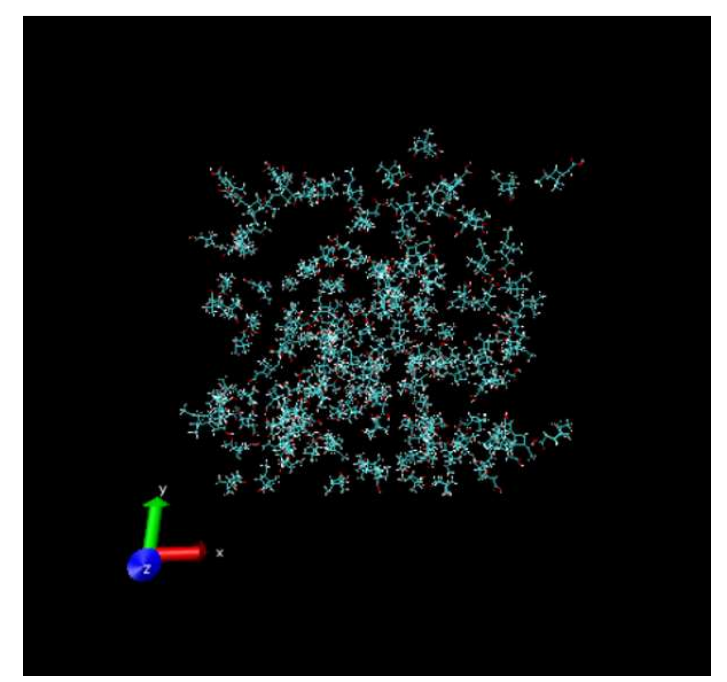

(b)

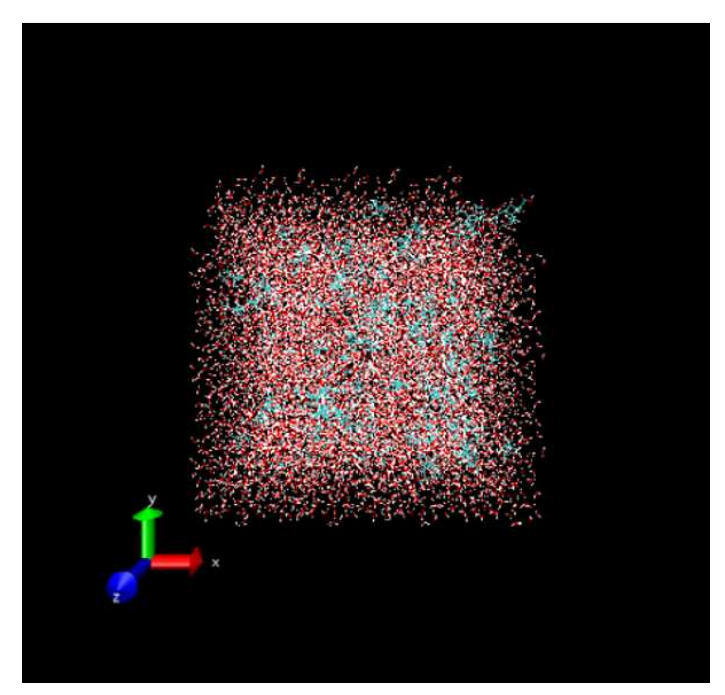

(c)

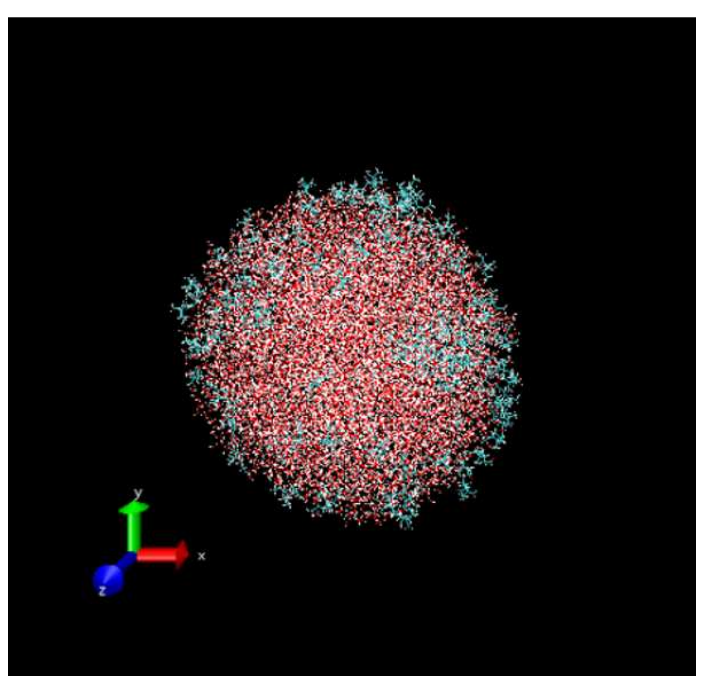

Fig. 2. (a) Molecules randomly distributed in a cubic box; (b) 10000 water molecules added; (c) the system adapts to a sphere with surfactants on the surface after 8 ns of simulation. 

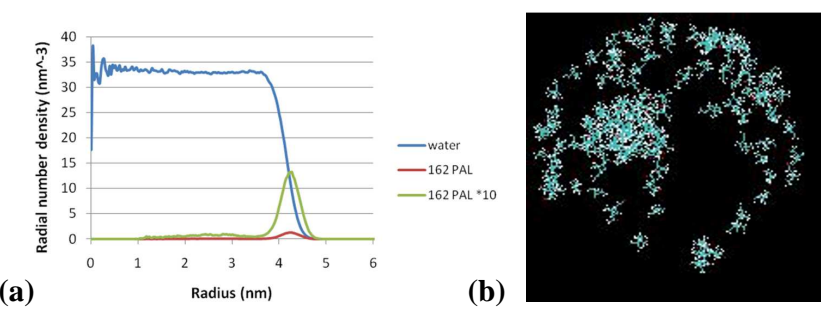

Fig. 3. (a) 162 PAL molecules aggregate near the surface leading to a large peak for radial number density at $4.2 \mathrm{~nm}$. The green line is the radial number density of the PAL molecules multiplied with a factor of 10. (b) System containing 162 PAL molecules; crosssection picture.
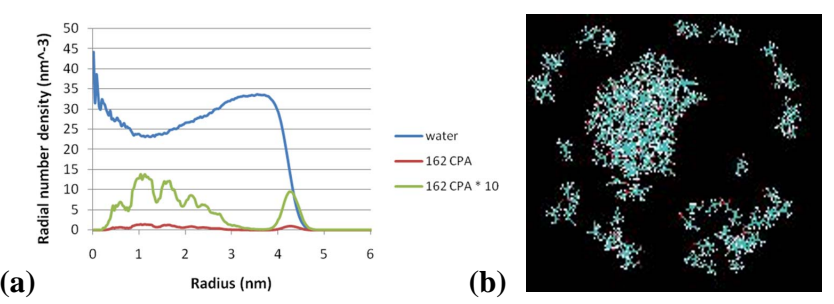

Fig. 4. (a) Radial number density showing two main peaks at 1.1 and $4.2 \mathrm{~nm}$. The green line is the radial number density of the CPA molecules multiplied with a factor of 10. (b) System containing 162 CPA molecules; cross-section picture.

corresponding snapshot for the system taken at $6 \mathrm{~ns}$. From the figures, we can see that the aggregate is not entirely centered in the clusters, but rather near the surface, contributing to the radial number density peak at the radius of the cluster at $4.2 \mathrm{~nm}$. So far, aggregates that accumulate on the surface are found to be stable and could remain on the surface. The water molecules are not shown in Fig. 3 and the cluster is shown in cross-section view. The value for radial number density is determined as a mean over the time from the production simulation.

Figure $4 \mathrm{a}$ shows the radial number density of the system with $162 \mathrm{CPA}$ and 10000 water molecules. From the figure, we can find that the accumulation of CPA molecules in the volume element is between 1 and $3 \mathrm{~nm}$ and in the region of the bell-shaped peak at $4.2 \mathrm{~nm}$. This means that for this system, the aggregation can be found even in the inner part of the cluster. Figure $4 \mathrm{~b}$ shows a snapshot of the cluster taken at $6 \mathrm{~ns}$, where the water molecules are removed for clarity.

The two types of aggregate formation for CPA and PAL discussed are also applicable to PAD, which showed similar behavior. Either there is (a) no aggregate formation, (b) aggregate formation in the interior of the cluster or (c) aggregate formation near the surface. This is valid for all three model HULIS compounds.
The findings of aggregates in the water clusters may be of importance both for the dynamics of the droplets and for their growth. Similar results have been reported by Virtanen et al. (2010) for plant chamber experiments, where volatile organic compounds are found to be in an amorphous solid state.

\subsection{Surface tension calculations}

The surface tension is the computed effective surface tension $\tilde{\gamma}_{e}$ from the procedure described by Zakharov et al. (1997). The diameter of the clusters varies between $8.28 \mathrm{~nm}$ and $8.60 \mathrm{~nm}$.

Because each water molecule near the surface interacts with fewer neighboring water molecules, surface tension is created. The effect is less pronounced in a sphere than in a planar interface. The smaller the sphere, the less prominent the effect would be. For pure water, the surface tension for liquid-gas interface calculated using the SPC/E water model is $57.0 \mathrm{mN} \mathrm{m}^{-1}$ for a sphere with radius of $4.3 \mathrm{~nm}$ and $65.0 \mathrm{mN} \mathrm{m}^{-1}$ for a planar interface (Bahadur and Russel, 2008). Experimental data give a higher value for the planar liquid-gas interface, which is $71.97 \mathrm{mN} \mathrm{m}^{-1}$ at $298 \mathrm{~K}$. It is common for water models to give surface tensions different from the experimental values, as few force field models can reproduce the experimental surface tensions accurately (Chen and Smith, 2007). The general behavior of the system, however, is not affected. Compared to many other water models, the SPC/E model is able to give the surface tensions closer to the experimental values. Although the much more recent TIP4P/2005 water model (Abascal and Vega, 2005) is able to yield better surface tension than SPC/E at the cost of an extra interacting site, in this work we employ the SPC/E water model for computational efficiency and to keep consistency with our previous study (Li et al., 2010). The deviation of the surface tension of a spherical system of 10000 water molecules from that of a planar interface is not crucial, since results for surface tension measurements in spherical clusters show a good resemblance of the trend with experimental data even for a system of half the size, 5000 water molecules ( $\mathrm{Li}$ et al., 2010).

The calculated surface tension values are listed in Table 2 . As we can see from the table, the surface tension decreases significantly when model HULIS compounds molecules are involved. CPA is more effective than PAD or PAL molecules in reducing the surface tension. With a CPA concentration of $0.07 \mathrm{~mol} \mathrm{~L}^{-1}$, the surface tension of the cluster becomes $46.2 \mathrm{mN} \mathrm{m}^{-1}$, corresponding to a reduction of the surface tension by about $19 \%$. For the cluster with highest CPA concentration $\left(0.81 \mathrm{~mol} \mathrm{~L}^{-1}\right)$, a reduction of $38 \%$ of the surface tension was found. 
Table 2. Surface tension for the systems simulated.

\begin{tabular}{|c|c|c|c|}
\hline System simulated & Concentration $\left(\mathrm{mol} \mathrm{L}^{-1}\right)$ & Surface tension $\left(\mathrm{mN} \mathrm{m}^{-1}\right)$ & Surface tension $(\%)$ \\
\hline 10000 water & 0.00 & $57.0^{*}$ & 100.0 \\
\hline $13 \mathrm{CPA}+10000$ water & 0.07 & 46.2 & 81.1 \\
\hline $27 \mathrm{CPA}+10000$ water & 0.15 & 45.0 & 78.9 \\
\hline $54 \mathrm{CPA}+10000$ water & 0.27 & 42.4 & 74.4 \\
\hline $81 \mathrm{CPA}+10000$ water & 0.40 & 38.7 & 67.9 \\
\hline $162 \mathrm{CPA}+10000$ water & 0.81 & 35.3 & 61.9 \\
\hline 13 PAD + 10000 water & 0.07 & 52.2 & 91.6 \\
\hline 27 PAD + 10000 water & 0.15 & 48.2 & 84.6 \\
\hline 54 PAD + 10000 water & 0.29 & 45.1 & 79.1 \\
\hline $81 \mathrm{PAD}+10000$ water & 0.43 & 40.6 & 71.2 \\
\hline $162 \mathrm{PAD}+10000$ water & 0.86 & 40.1 & 70.4 \\
\hline $13 \mathrm{PAL}+10000$ water & 0.07 & 49.8 & 87.4 \\
\hline $27 \mathrm{PAL}+10000$ water & 0.15 & 45.7 & 80.2 \\
\hline $54 \mathrm{PAL}+10000$ water & 0.30 & 44.2 & 77.5 \\
\hline $81 \mathrm{PAL}+10000$ water & 0.45 & 40.6 & 71.2 \\
\hline $162 \mathrm{PAL}+10000$ water & 0.88 & 34.0 & 59.6 \\
\hline
\end{tabular}

* Value taken from Bahadur and Russel (2008).

\subsubsection{Szyszkowski parameters}

Table 3 shows the Szyszkowski equation parameters $E$ and $D$ (see Eq. 5) for CPA. The data was determined through least squares fit of the Langmuir-Gibbs relation, described in Li et al. (2010). The constant $D$ is dimensionless.

The experimental data from Tuckermann (2007) are in accordance to this study, since the Szyszkowski parameters $E$ and $D$ are similar in magnitude to in this study. This produces Szyszkowski curves that are almost overlapping and the theoretical values for surface tension are close to the experimental data.

It can be seen that there is a significant increase in the constant $E$ compared to Li et al. (2010) and also an almost $50 \%$ reduction of $D$, giving the graph of the 10000 water system (Fig. 5) a much better resemblance to the experimental data by Shulman (1996). A part of the deviation from the ideal Szyszkowski graph may be explained by the aggregation formation in the nanoaerosol clusters. Therefore it may lead to an uncertainty in determining the surface tension of droplets containing these model HULIS compounds. The deviation by Kiss et al. from the other experimental data is due to the fact that the real aerosol particles with HULIS were examined which have even stronger surfactant effects than model HULIS compounds (Kiss et al. 2005).

In Table 4, we list the Szyszkowski parameters $E$ and $D$ for the three compounds CPA, PAD and PAL. The latter two have not been experimentally determined previously under atmospheric conditions.

In Fig. 6 the graphs of the Szyszkowski equation for the three compounds are shown. It should be noted that there are two anomalies in the data points of $54 \mathrm{PAL}$ and of 162

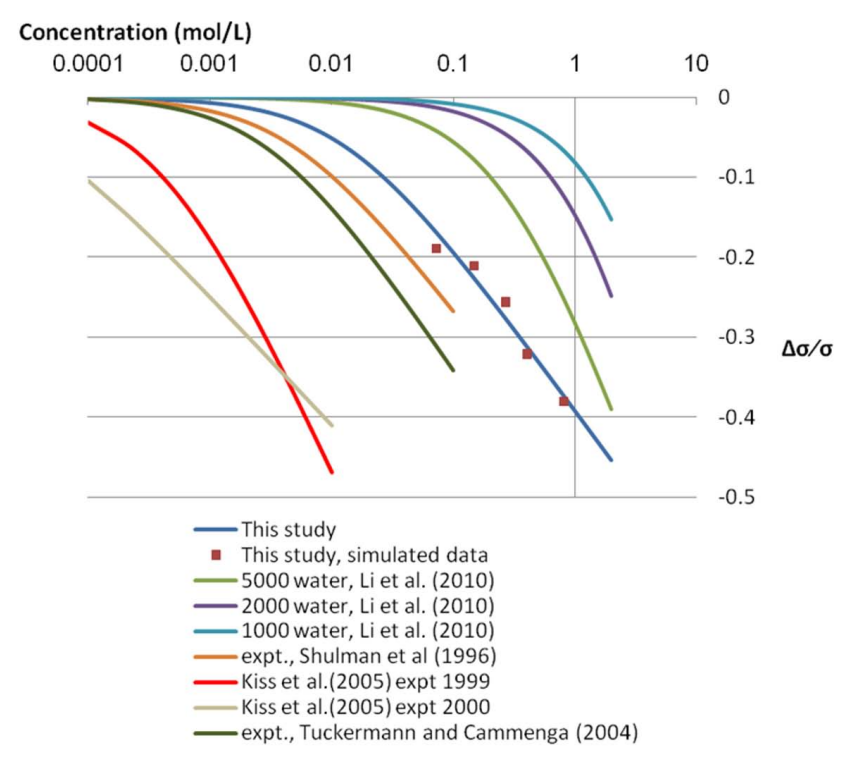

Fig. 5. Fitted Szyszkowski curves from five different studies.

PAD, the latter affecting the graph in such a way that the slope is diminished severely. These anomalies reflect the difficulties in computing the surface tensions in clusters with model HULIS compounds aggregates. However, it can still be observed that CPA shows a larger effect on surface tension reduction at lower concentrations. At higher concentrations, all the model HULIS compounds can reduce greatly the surface tensions. 
Table 3. Szyszkowski parameters $E$ and $D$ from three different studies.

\begin{tabular}{|c|c|c|}
\hline Number of water molecules & $E\left(\mathrm{~L} \mathrm{~mol}^{-1}\right)$ & $D$ \\
\hline $1000^{1}$ & 0.1454 & 0.6007 \\
\hline $2000^{1}$ & 0.5484 & 0.3348 \\
\hline $5000^{1}$ & 3.4499 & 0.1884 \\
\hline This study, CPA & 75.1282 & 0.0905 \\
\hline Shulman et al. $(1996)^{2}$ & 212.4109 & 0.0864 \\
\hline Kiss et al. $(2005)^{3}$ & 2408.3007 & 0.1457 \\
\hline Kiss et al. $(2005)^{4}$ & 33680.9872 & 0.0704 \\
\hline Tuckermann and Cammenga (2004) ${ }^{2}$ & 315.3176 & 0.0981 \\
\hline Tuckermann $(2007)^{2}$ & 41.3025 & 0.0813 \\
\hline
\end{tabular}

${ }^{1}$ Data from Li et al. (2010); ${ }^{2}$ Experimental data; ${ }^{3}$ Experimental data, September $1999 ;{ }^{4}$ Experimental data, April-May, 2000.

Table 4. Szyszkowski parameters $E$ and $D$ for the three model HULIS compounds.

\begin{tabular}{lll}
\hline Compound & $E\left(\mathrm{~L} \mathrm{~mol}^{-1}\right)$ & $D$ \\
\hline CPA & 75.1282 & 0.0905 \\
PAD & 21.8899 & 0.1066 \\
PAL & 24.3134 & 0.1292 \\
\hline
\end{tabular}

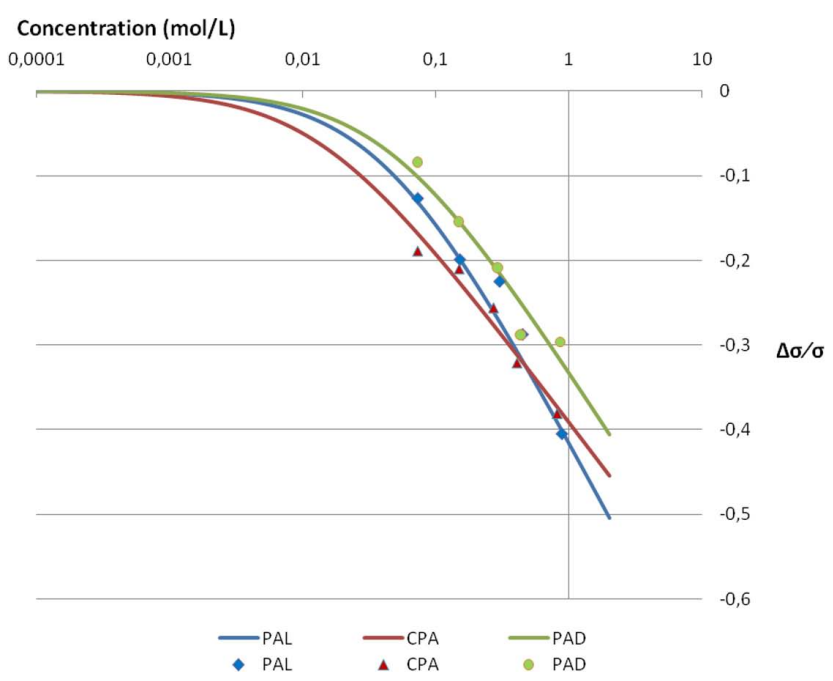

Fig. 6. Szyszkowski graph - comparison between the three model HULIS compounds.

\subsubsection{Köhler curves}

In Fig. 7, the calculated Köhler curves are displayed for a $0.1 \mu \mathrm{m}$ diameter dry CPA CCN. The green curve shows the calculated Köhler curve when using the value of $0.073 \mathrm{~N} \mathrm{~m}^{-1}$ for pure water. The red and cyan curves are using 0.05 and 0.03 , respectively, as examples of reduced surface tension due to the CPA activity. Blue curve shows the

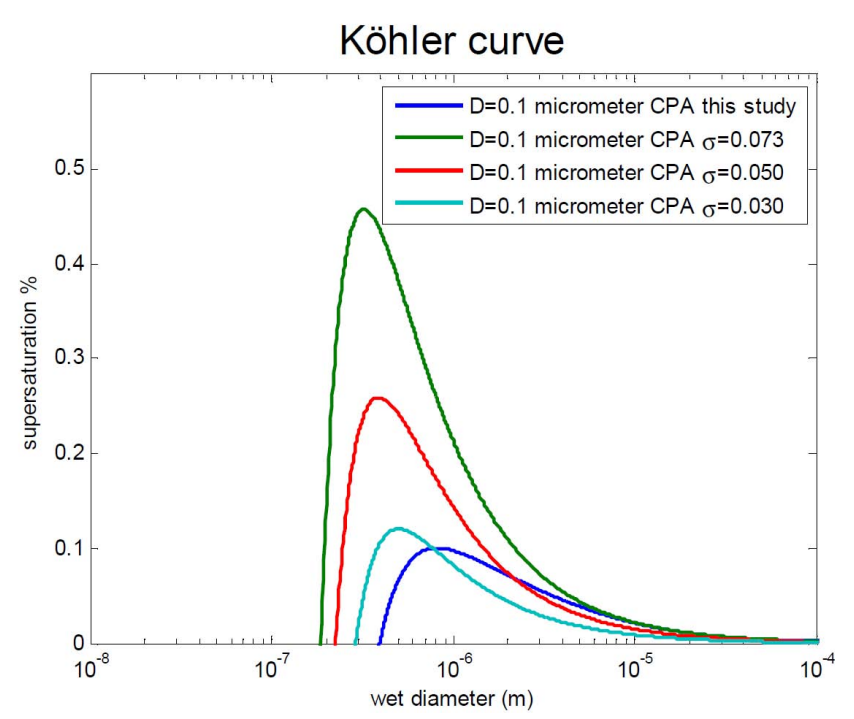

Fig. 7. Köhler curves with and without compensation for variable values for surface tension, determined by the Szyszkowski equation, using values for parameters $D$ and $E$ from this study. Dry diameters are in the four curves $0.1 \mu \mathrm{m}$.

calculated Köhler curve under same conditions stated above, with the difference that the value for surface tension is not a constant, but is calculated from the Szyszkowski equation (Eq. 5). The values for the Szyskowski parameters $D$ and $E$, assumed to be for larger droplets, are taken from this study.

As can be seen from Fig. 7, the Köhler curve in the case of variable surface tension shows that a lower supersaturation is needed for cloud droplet formation and growth, indicating that a greater number of cloud droplets may form and thereby the cloud albedo will increase. On the other hand, it can be seen that the critical supersaturation is shifted towards larger diameters. The low solubility of CPA is taken into account by the fact that not all CPA molecules contribute to lowering of the surface tension, but aggregate instead of concentrating at the surface. 
The concentrations in this work are about 1-2 order of magnitude higher than observed experimentally (Shulman et al., 1996). However, we have shown that the increase of the Szyszkowski parameter $E$ for larger systems, which is approaching the experimental value (Shulman et al., 1996), is a convincing indication that the method of MD simulations is valid. It is even probable that the use of MD might be even more powerful when investigating larger systems, which will be a future task to show. Preliminary results show that the Aitken mode particles with larger sizes could be covered and the Köhler equation could be improved by incorporating surface tension corrections ( $\mathrm{Li}$ et al., 2011).

\section{Concluding remarks}

In this study we have shown that MD simulation is an effective tool for investigating the properties of nanoaerosols such as surface tension, surface to bulk distribution and aggregation formation for model HULIS compounds. The advantage of MD simulations is that they could provide us the microscopic details which are often hard to observe experimentally, such as the structures and aggregation formation of nano-sized aerosol clusters.

By comparison to experimental studies (Shulman et al., 1996), parameters of an expanded Köhler equation that takes a variable value for surface tension from the Szyskowski equation (Eq. 5) into account could be used even for previously undetermined model HULIS compounds PAD and PAL. The MD method gives us a tool for deriving the Szyszkowski parameters for almost any surface active compound.

This study further reveals, for larger particles of pure CPA, a reduction of critical supersaturation. This may result in the formation of more activated cloud droplets and an increased albedo (Facchini et al., 1999b; Rodhe, 1999). It may even be so that the cloudiness and type of cloud formation over highly vegetated areas are misjudged in climate models as a result of the effect of lowering the surface tension of cloud droplets. There may also be other surface active compounds that affect cloud formation in various types of settings that are worth examining.

The findings of this study that model HULIS compounds during certain conditions aggregate inside nanoaerosol clusters could have implications of various aspects when describing and parameterizing $\mathrm{CCN}$ and cloud droplets containing model HULIS compounds. Even physical and chemical properties of $\mathrm{CCN}$ and cloud droplets could be affected by the ability for model HULIS compounds to aggregate. Therefore, aggregation formation in aerosols is probably also a key factor in cloud microphysics.
Acknowledgements. T. H. and C. L. acknowledge the support from Research School for Teachers on Climate Evolution and Water Resources, Stockholm University, Sweden. H. Å. acknowledges a grant from the Swedish Science Research council; Nucleation, stability and light-absorption of pollutant particles (contract 20093614). The authors also acknowledge a grant from the Swedish Infrastructure Committee (SNIC) for the project "Multiphysics Modelling of Molecular Materials", SNIC 022/09-25.

Edited by: D. Knopf

\section{References}

Abascal, J. L. F. and Vega, C.: A general purpose model for the condensed phases of water: TIP4P/2005, J. Chem. Phys., 123, 234505, doi:10.1063/1.2121687, 2005.

Bahadur, R. and Russel, L. M.: Effect of surface tension from MD simulations on size-dependent deliquescence of $\mathrm{NaCl}$ nanoparticles, Aerosol Sci. Tech., 42, 369-376, 2008.

Berendsen, H. J. C., Grigera, J. R., and Straatsma, T. P.: The missing term in effective pair potentials, J. Phys. Chem., 91, 6269-6271, 1987.

Chakraborty, P. and Zachariah, M. R.: Sticking coefficient and processing of water vapor on organic coated nanoaerosols, J. Phys. Chem. A, 112, 966-972, 2008.

Chen, F. and Smith, P. E.: Simulated surface tensions of common water models, J. Chem. Phys., 126, 221101, doi:10.1063/1.2745718, 2007.

Cini, R., Innocenti, N. D., Loglio, G., Oppo, C., Orlandi, G., Stortini, A. M., Tesei, U., and Udisti, R.: Air-sea exchange: sea salt and organic micro components in Antarctic snow, Int. J. Environ. An. Chem., 63, 15-27, 1996.

Darden, T., York, D., and Pedersen, L.: Particle mesh ewald: an N$\log (\mathrm{N})$ method for Ewald sums in large systems, J. Chem. Phys., 98, 10089-10092, 1993.

Decesari, S., Facchini, M. C., Matta, E., Lettini, F., Mircea, M., Fuzzi, S., Tagliavini, E., and Putaud, J. P.: Chemical features and seasonal variation of fine aerosol water-soluble organic compounds in the Po Valley, Italy, Atmos. Environ., 35, 3691-3699, 2001.

Essmann, U., Perera, L., Berkowitz, M. L., Darden, T., Lee, H., and Pedersen, L. G.: A smooth particle mesh Ewald potential, J. Chem. Phys., 103, 8577-8592, 1995.

Facchini, M. C., Fuzzi, S., Zappoli, S., Andracchio, A., Gelencser, A., Kiss, G., Krivacsy, Z., Meszaros, E., Hansson, H. C., Alsberg, T., and Zebuhr, Y.: Partitioning of the organic aerosol component between fog droplets and interstitial air, J. Geophys. Res., 104, 26821-26832, 1999a.

Facchini, M. C., Mircea, M., Fuzzi, S., and Charlson, R. J.: Cloud albedo enhancement by surface-active organic solutes in growing droplets, Nature, 401, 257-259, 1999b.

Facchini, M. C., Decesari, S., Mircea, M., Fuzzi, S., and Loglio, G.: Surface tension of atmospheric wet aerosol and cloud/fog droplets in relation to their organic carbon content and chemical composition, Atmos. Environ., 34, 4853-4857, 2000.

Forster, P., Ramaswamy, V., Artaxo, P., Berntsen, T., Betts, R., Fahey, D. W., Haywood, J., Lean, J., Lowe, D. C., Myhre, G., Nganga, J., Prinn, R., Raga, G., Schulz, M., and Van Dorland, R.: Changes in Atmospheric Constituents and in Radiative Forcing, 
in: Climate Change 2007: The Physical Science Basis. Contribution of Working Group I to the Fourth Assessment Report of the Intergovernmental Panel on Climate Change, chap. 2, edited by: Solomon, S., Qin, D., Manning, M., Chen, Z., Marquis, M., Averyt, K. B., Tignor, M., and Miller, H. L. Cambridge University Press, Cambridge, UK and New York, NY, USA, 131-234, 2007.

Fu, P., Kawamura, K., Chen, J., and Barrie, L. A.: Isoprene, monoterpene, and sesquiterpene oxidation products in the high arctic aerosols during late winter to early summer, Environ. Sci. Technol., 43, 4022-4028, 2009.

Hess, B.: P-lincs: a parallel linear constraint solver for molecular simulation, J. Chem. Theory Comput., 4, 116-122, 2007.

Hess, B., Bekker, H., Berendsen, H. J. C., and Fraaije, J. G. E. M.: LINCS: a linear constraint solver for molecular simulations, J. Comput. Chem., 18, 1463-1472, 1997.

Hess, B., Kutzner, C., van der Spoel, D., and Lindahl, E.: GROMACS 4: algorithms for highly efficient, load-balanced, and scalable molecular simulation, J. Chem. Theory Comput., 4, 435-447, 2008.

Hoover, W. G.: Canonical dynamics: Equilibrium phasespace distributions, Phys. Rev. A, 31, 1695-1697, doi:10.1103/PhysRevA.31.1695, 1985.

Humphrey, W., Dalke, A., and Schulten, K.: VMD - visual molecular dynamics, J. Mol. Graphics, 14, 33-38, 1996.

Jorgensen, W. L., Maxwell, D. S., and Tirado-Rives, J.: Development and testing of the OPLS all-atom force field on conformational energetics and properties of organic liquids, J. Am. Chem. Soc., 118, 11225-11236, 1996.

Kiss, G., Tombácz, E., and Hansson, H.-C.: Surface tension effects of humic-like substances in the aqueous extract of tropospheric fine aerosol, J. Atmos. Chem., 50, 279-294, 2005.

Leach, A. R.: Molecular Modeling Principles and Applications, Pearson Education Ltd., Harlow, 2001.

Li, X., Hede, T., Tu, Y., Leck, C., and Ågren, H.: Surface-active cis-pinonic acid in atmospheric droplets: a molecular dynamics study, J. Phys. Chem. Lett., 1, 769-773, 2010.

Li, X., Hede, T., Tu, Y., Leck, C., and Ågren H.: Glycine in aerosol water droplets: A critical assessment of Köhler theory by predicting surface tension from molecular dynamics simulations, Atmos. Chem. Phys., 11, 519-527, doi:10.5194/acp-11-519-2011, 2011.

Köhler, H.: The nucleus in and the growth of hygroscopic droplets, T. Faraday Soc., 32, 1152-1161, 1936.

Meissner, H. P. and Michaels, A. S.: Surface tensions of pure liquids and liquid mixtures, Ind. Eng. Chem., 41, 2782-2787, 1949.

Nijmeijer, M. J. P., Bruin, C., van Woerkom, A. B., and Bakker, A. F.: Molecular dynamics of the surface tension of a drop, J. Chem. Phys., 96, 565-576, 1992.

Novakov, T. and Penner, J. E.: Large contribution of organic aerosols to cloud condensation nuclei concentrations, Nature, 365, 823-826, 1993.
O’Dowd, C. D., Aalto, P., Hämeri, K., Kulmala, M., and Hoffmann, T.: Atmospheric particles from organic vapours, Nature, 416, 497-498, 2002.

Rodhe, H.: Clouds and climate, Nature, 401, 223-224, 1999.

Samburova, V., Zenobi, R., and Kalberer, M.: Characterization of high molecular weight compounds in urban atmospheric particles, Atmos. Chem. Phys., 5, 2163-2170, doi:10.5194/acp-52163-2005, 2005.

Shivakumar, D., Williams, J., Yujie, W., Damm, W., Shelley, J. and Sherman W.: Prediction of absolute solvation free energies using molecular dynamics free energy perturbation and the OPLS force field, J. Chem. Theory Comput., 6, 1509-1519, doi:10.1021/ct900587b, 2010.

Shulman, M. L., Jacobson, M. C., Charlson, R. J., Synovec, R. E., and Young, T. E.: Dissolution behavior and surface tension effects of organic compounds in nucleating cloud droplets, Geophys. Res. Lett., 23, 277-280, 1996.

van der Spoel, D., Lindahl, E., Hess, B., van Buuren, A. R., Apol, E., Meulenhoff, P. J., Tieleman, D. P., Sijbers, A. L. T. M., Feenstra, K. A., van Drunen, R., and Berendsen, H. J. C.: Gromacs User Manual version 4.0, available online at: www.gromacs.org, last access: 15 November 2010, 2005.

Szyszkowski, B.: Experimentelle studien über kapilläre eigenschaften der wässrigen, Z. Phys. Chem., 64, 385-414, 1908.

Sorjamaa, R., Svenningsson, B., Raatikainen, T., Henning, S., Bilde, M., and Laaksonen, A.: The role of surfactants in Köhler theory reconsidered, Atmos. Chem. Phys., 4, 2107-2117, doi:10.5194/acp-4-2107-2004, 2004.

Tanford, C.: The Hydrophobic Effect: Formation of Micelles and Biological Membranes, John Wiley \& Sons Inc, New York, NY, USA, 1973.

Tuckermann, R. and Cammenga, H. K.: The surface tension of aqueous solutions of some atmospheric water-soluble organic compounds, Atmos. Environ., 38, 6135-6138, 2004.

Tuckermann, R.: Surface tension of aqueous solutions of watersoluble organic and inorganic compounds, Atmos. Environ., 41, 6265-6275, 2007.

Varga, Z., Kiss, G., and Hansson, H.-C.: Modelling the cloud condensation nucleus activity of organic acids on the basis of surface tension and osmolality measurements, Atmos. Chem. Phys., 7, 4601-4611, doi:10.5194/acp-7-4601-2007, 2007.

Virtanen, A., Joutsensaari, J., Koop, T., Kannosto, J., Yli-Pirilä, P., Leskinen, J., Mäkelä, J. M., Holopainen, J. K., Pöschl, U., Kulmala, M., Worsnop, D. R., and Laaksonen, A.: An amorphous solid state of biogenic secondary organic aerosol particles, Nature, 467, 824-827, 2010.

Zakharov, V. V., Brodskaya, E. N., and Laaksonen, A.: Surface tension of water droplets: a molecular dynamics study of model and size dependencies, J. Chem. Phys., 107, 10675-10683, 1997.

Zakharov, V. V., Brodskaya, E. N., and Laaksonen, A.: Surface properties of water clusters: a molecular dynamics study, Mol. Phys., 95, 203-208, 1998. 